Article

\title{
Assisting Flood Disaster Response with Earth Observation Data and Products: A Critical Assessment
}

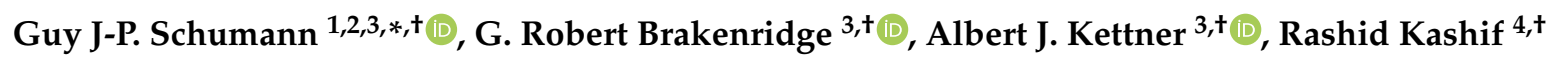 \\ and Emily Niebuhr ${ }^{5,+}$ \\ Remote Sensing Solutions, Inc., Monrovia, CA 91016, USA \\ 2 School of Geographical Sciences, University of Bristol, BS81SS Bristol, UK \\ 3 INSTAAR, University of Colorado Boulder, Boulder, CO 80303, USA; \\ robert.brakenridge@colorado.edu (G.R.B.); albert.kettner@colorado.edu (A.J.K.) \\ 4 Self, Pelham, NH 03076, USA; rashid.kashif.4@gmail.com \\ 5 NOAA National Weather Service, Anchorage, AK 91016, USA; elniebuhr@gmail.com \\ * Correspondence: gjpschumann@gmail.com \\ + These authors contributed equally to this work.
}

Received: 22 June 2018; Accepted: 3 August 2018; Published: 6 August 2018

\begin{abstract}
Floods are among the top-ranking natural disasters in terms of annual cost in insured and uninsured losses. Since high-impact events often cover spatial scales that are beyond traditional regional monitoring operations, remote sensing, in particular from satellites, presents an attractive approach. Since the 1970s, there have been many studies in the scientific literature about mapping and monitoring of floods using data from various sensors onboard different satellites. The field has now matured and hence there is a general consensus among space agencies, numerous organizations, scientists, and end-users to strengthen the support that satellite missions can offer, particularly in assisting flood disaster response activities. This has stimulated more research in this area, and significant progress has been achieved in recent years in fostering our understanding of the ways in which remote sensing can support flood monitoring and assist emergency response activities. This paper reviews the products and services that currently exist to deliver actionable information about an ongoing flood disaster to emergency response operations. It also critically discusses requirements, challenges and perspectives for improving operational assistance during flood disaster using satellite remote sensing products.
\end{abstract}

Keywords: flood disaster; response assistance; remote sensing; interoperability

\section{Introduction}

Remote sensing technology, particularly from space, allows measurements to be obtained over spatial scales much larger than may be covered by field-based instruments and methods. For large-scale phenomena, such as flooding, this is particularly appealing and for about four decades now, satellite data of inundation have been used to obtain information about flooding across various spatial and temporal scales, typically in the form of flooded area. The position of the maximum flood shoreline is the main variable to determine the extent of flood hazard.

During the last two decades, the amount of satellite missions carrying instruments that can be utilized to map flooding has increased considerably and there is now a general consensus among space agencies and scientists to strengthen the support that satellites can offer for flood monitoring. Generally speaking, there are commonly two types of sensors for mapping floods around the world, optical and radar (microwave). Images from optical sensors (available since the mid 1970s) now form 
a valuable historical record and mapping floods is relatively straightforward from these type of images provided that there is no cloud cover and that vegetation cover and built-up areas are not too dense. In fact, early investigative studies on the use of satellite imagery of floods [1,2] already demonstrated the potential to improve our understanding of flood processes and even speculated on the value such data may have for economic sectors, such as the insurance markets.

With the advent of synthetic aperture radar (SAR), the availability of satellite images of floods has proliferated [3], especially since the mid 1990s. This situation has continued to improve particularly over the past decade with launches of very high-resolution SAR satellites (e.g., TerraSAR-X, DLR (German Aerospace Center), Radarsat-2, CSA (Canadian Space Agency)) and also constellations of those (COSMO-SkyMed, ASI (Italian Space Agency), Sentinel-1, ESA (European Space Agency)). For flood mapping, SAR has the advantage to penetrate cloud cover and remains largely unaffected by adverse weather conditions that often persist during high-impact flood events [4]. This has led to greater reliability in flood mapping and accelerated progress in flood forecasting and flood inundation model development, particularly in the area of model calibration and validation [5-11], and more recently also assimilation [12-14].

Recently, several papers have been published that review commonly used methods for mapping floods from both SAR [4,15,16] and optical [17-19] satellite sensors. The reader is referred to these review papers for details on current state-of-the-art techniques and uses of specific imagery data. Table 1 provides a concise list of the sensors typically used in flood mapping and briefly discusses the main advantages of both sensor types (SAR and optical).

Table 1. List of satellite sensors, still active, that are typically used in operational or semi-operational flood mapping.

\begin{tabular}{ccccc}
\hline Satellite/Sensor & Agency & Sensor Type & Start Date & Advantage * \\
\hline Landsat & NASA/USGS & Multispectral & $1972-$ & Long historic archive \\
\hline MODIS Terra/Aqua & NASA & Multispectral & 1999-/2002- & Sub-daily repeat \\
\hline TerraSAR-X & DLR & SAR X-band & 2007- & Available in 3 m resolution mode \\
\hline COSMO-SkyMed & ASI & SAR X-band & 2007- & $\begin{array}{c}\text { Constellation of four satellites } \\
\text { providing high-repeat coverage } \\
\text { of up to 1 m resolution }\end{array}$ \\
\hline Sentinel-1 & NASA/NOAA & Multispectral & 2011- & Operational mission \\
\hline ALOS-PALSAR 2 & JAXA & SAR C-band & 2014- & $\begin{array}{c}\text { Open data access constellation } \\
\text { of two satellites }\end{array}$ \\
\hline Sentinel-2 & ESA/Copernicus & Multispectral & 2015- & Open data access constellation \\
of two satellites
\end{tabular}

* Please note that only the main advantage is listed. 
As a direct consequence of the significant progress in research in recent years, the science of remote sensing of floods has now become mature enough to deliver products and services for decision-making and operational applications, such as flood disaster response assistance. However, this is not without any obstacles, and the main challenge lies in maintaining adequate targeted application readiness levels and high interoperability of products and services being delivered.

To better understand the needs for flood disaster assistance from the disaster response end-user perspective as well as the challenges this poses to scientists and product developers, this paper briefly reviews existing and established, publicly-available (as opposed to owned by an independent or commercial entity), satellite products and services made available to end-users active in flood disaster response and then critically discusses requirements for improving operational assistance during flood disaster using satellite remote sensing products.

It should be noted that there are many more Earth Observation (EO)-based products and services that are becoming available to assist disaster response than are reported hereafter (see Alfieri et al. [20] for more specific case studies).

\section{Existing Products and Services}

In the case of flood monitoring and response, several organizations, including space agencies such as NASA (National Aeronautics and Space Administration) and ESA (European Space Agency) as well as many, universities and research institutes, already provide several services including imagery and computer simulation products during an event, either through ongoing activities at various national centers and agencies or via research funding, all of which need be maintained and sustained. There are also international initiatives and organizations, comprising of many different players, that provide relevant services and geospatial data. Table 2 provides a non-exhaustive list of the most relevant entities that provide operational and open-access services during major flood disasters.

As is evident from Table 2, nearly all systems or initiatives currently active and operated under a public, open-access policy, are either voluntary or based on limited project funding, with the exception of the Disaster Charter and the Copernicus program. In other words, none of those systems are sustained and managed in the long run without continuous funding and commitment. There is thus little guarantee that they will be around after motivation or funding cease, albeit heroic efforts that are constantly made to secure periodic funding and find new enthusiastic volunteers for tasks at hand.

The next sections give a brief description of each of the systems listed in Table 2, followed by a discussion of capabilities, needs and expectations. From this, the paper then draws some prospective actions. 
Table 2. List of available EO services with potential for flood response assistance, including capabilities and level of expectation.

\begin{tabular}{|c|c|c|c|c|c|}
\hline System & Organization * & Operational & Data/Service Type & Priority Challenge to be Addressed & Level of Expectation ** \\
\hline MODIS/Landsat NRT flood maps & NASA/GSFC & Yes & $\begin{array}{c}\text { MODIS mapping } \\
\text { (Landsat mapping on request only) }\end{array}$ & $\begin{array}{l}\text { Cloud masking; Integration of } \\
\text { SAR uncertainty }\end{array}$ & High \\
\hline $\begin{array}{l}\text { Dartmouth Flood Observatory } \\
\text { (DFO) }\end{array}$ & $\begin{array}{l}\text { NASA/University } \\
\text { Colorado, Boulder }\end{array}$ & Yes & $\begin{array}{c}\text { MODIS-based mapping. Also, includes } \\
\text { mapping from other EO data during } \\
\text { selected events } \\
\end{array}$ & $\begin{array}{l}\text { Cloud masking; SAR-derived maps only for } \\
\text { selective events }\end{array}$ & High \\
\hline River Watch (DFO) & $\begin{array}{l}\text { NASA/University } \\
\text { Colorado, Boulder }\end{array}$ & Yes & Radiometry-based discharge & More sites needed; linking with flood model & High \\
\hline VIIRS/NPP & GMU/NOAA & No & Flood mapping & How to integrate with GSFC /DFO efforts & Moderate \\
\hline International Disaster Charter & Multiple space agencies & Yes (triggered) & Satellite imagery & How to clarify mechanisms and methods & High \\
\hline GFMS & NASA/UMD & Yes & $\begin{array}{c}\text { Numerical model using GPM data to } \\
\text { simulate discharge and extent }\end{array}$ & $\begin{array}{l}\text { Resolution; validation; coverage around dams; } \\
\text { improved web interface }\end{array}$ & High \\
\hline GFDS & GDACS/JRC & Yes & $\begin{array}{l}\text { Flood detection system (mainly based on } \\
\text { radiometry-derived discharge) }\end{array}$ & $\begin{array}{l}\text { How can this be integrated with other } \\
\text { agencies' efforts }\end{array}$ & Moderate \\
\hline ARIA & NASA/JPL & $\begin{array}{l}\text { Ad hoc with external } \\
\text { data coordination }\end{array}$ & $\begin{array}{l}\text { Multi-hazard mapping platform from } \\
\text { various satellite data }\end{array}$ & $\begin{array}{l}\text { Non-operational; more resources \& } \\
\text { funding required }\end{array}$ & Low \\
\hline G-POD Sarotec & ESA/LIST & $\begin{array}{l}\text { Yes but in } \\
\text { pre-operational status }\end{array}$ & On demand flood mapping from SAR & $\begin{array}{l}\text { In "beta" mode; next phase includes making } \\
\text { service operational \& complementary with } \\
\text { other agencies' efforts }\end{array}$ & Low \\
\hline ZKI & DLR & Yes & TerraSAR-X flood mapping & $\begin{array}{l}\text { Integrate with other agencies' efforts } \\
\text { and imagery }\end{array}$ & High \\
\hline Copernicus & European Commission & Yes & Disaster assistance & $\begin{array}{l}\text { How to speed up delivery of delineation and } \\
\text { grading maps and improve targeting }\end{array}$ & High \\
\hline GFP/GFWG & Global Flood Partnership & NA & Working group & $\begin{array}{l}\text { May be ideal to gather feedback; link } \\
\text { products closer to user and organize training } \\
\text { sessions; explores alternatives to collect } \\
\text { products during events }\end{array}$ & Low \\
\hline CEOS Flood Pilot & CEOS & No & Flood pilot (R\&D) & $\begin{array}{l}\text { Need to ensure continuity of this pilot and } \\
\text { related efforts (e.g., image licensing) }\end{array}$ & Low \\
\hline
\end{tabular}

* Please note that most systems listed require ongoing funding support; ${ }^{* *}$ The level of system/product performance and operationality that the end-user or decision-maker can expect. 


\subsection{The Dartmouth Flood Observatory and NASA's Near Real-Time Flood Mapping}

The Dartmouth Flood Observatory (DFO, http:/ / floodobservatory.colorado.edu) tracks, monitors and archives flood events globally since 1985 and makes data available to the public in various formats including graphics, spreadsheets and GIS maps. Since 2011, the DFO has collaborated with NASA in distributing near real-time (NRT) flood maps from satellite imagery, primarily from MODIS onboard NASA's Aqua and Terra satellites [21], and also related EO data. The DFO also archives this information. In addition, during high-impact flood disasters, the DFO maps flooding from other satellites, such as the Landsat series and SAR satellite missions, and aggregates these products to several map formats that assist flood response teams through situational awareness across large scale coverages.

More recently, the DFO has implemented an open geospatial service protocol. A Web Map Service (WMS) has been set up through which GIS clients can seamlessly ingest the latest up-to-date flood related products (Figure 1).

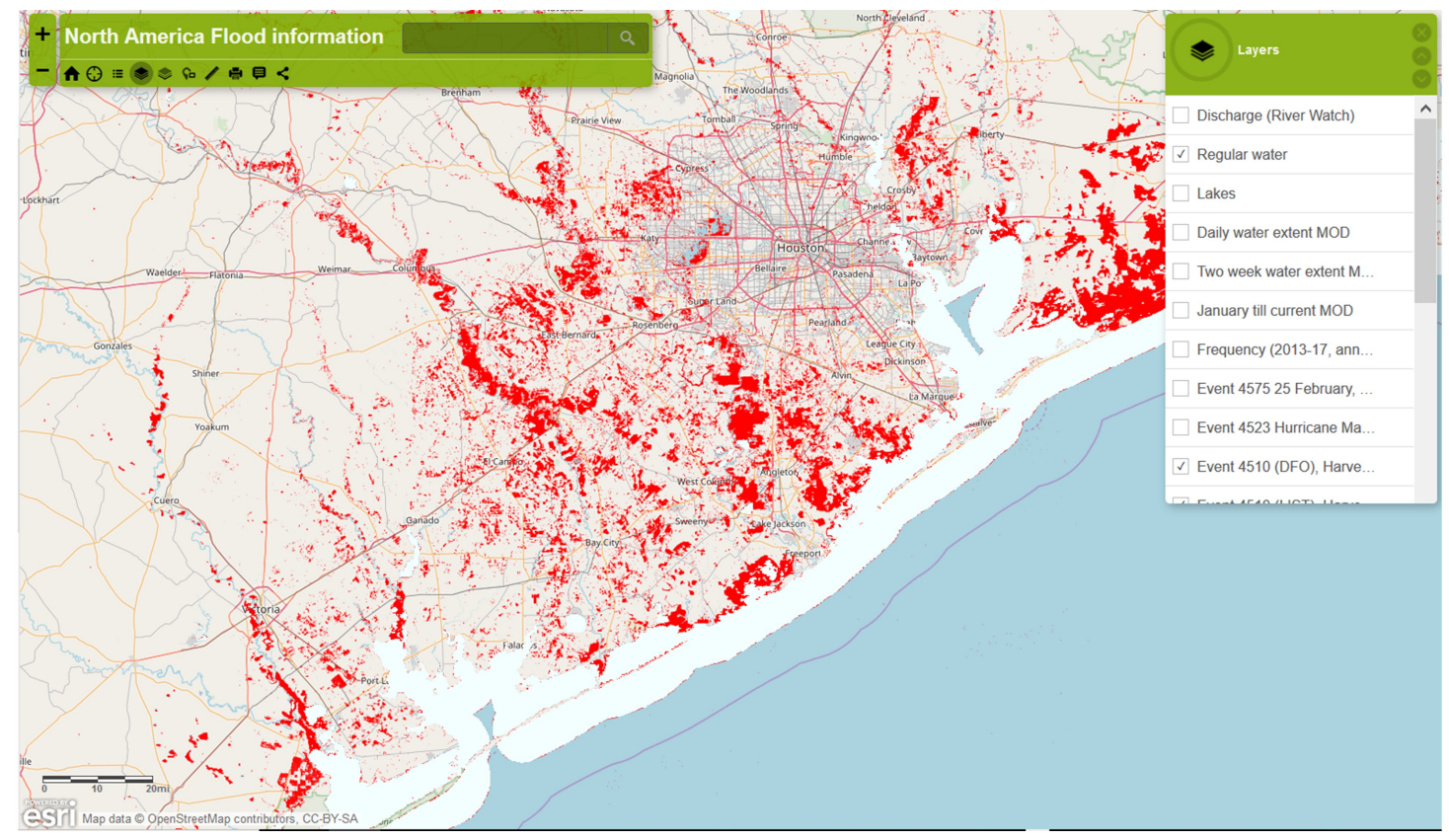

Figure 1. DFO's Web Map Service. Map overlaying the OpenStreetMap (https:/ / www.openstreetmap. org) shows in red flooding mapped during the Hurricane Harvey event from NASA MODIS, ESA Sentinel-1 (mapped by the Luxembourg Institute of Science and Technology and the DFO), ASI Cosmo-SkyMed, and CSA/MDA Radarsat-2 data.

The DFO also hosts a database of virtual stations of discharge records from 1998 until present based on an integration of microwave radiometry measurements and global hydrological modeling. The hydrological model (Water Balance Model, WBM [22]) is used for calibrating the microwave signal change (due to changes in surface water area occupying a pixel) to discharge. Specifically, these "River Watch" (http:/ / floodobservatory.colorado.edu/DischargeAccess.html) virtual stations [23] gauge the state of potential large river flooding daily based on changes in the brightness temperature of the passive microwave signal onboard the AMSR-E, TRMM, AMSR-2 and GPM sensors (Figure 2b). This information is regularly accessed by several humanitarian and flood disaster emergency management agencies, such as the United Nations World Food Programme (UN WFP). The DFO and related systems have been sustained by grants and contracts among others from NASA, the European Commission, the World Bank, and the Latin American Development Bank. 
(a)

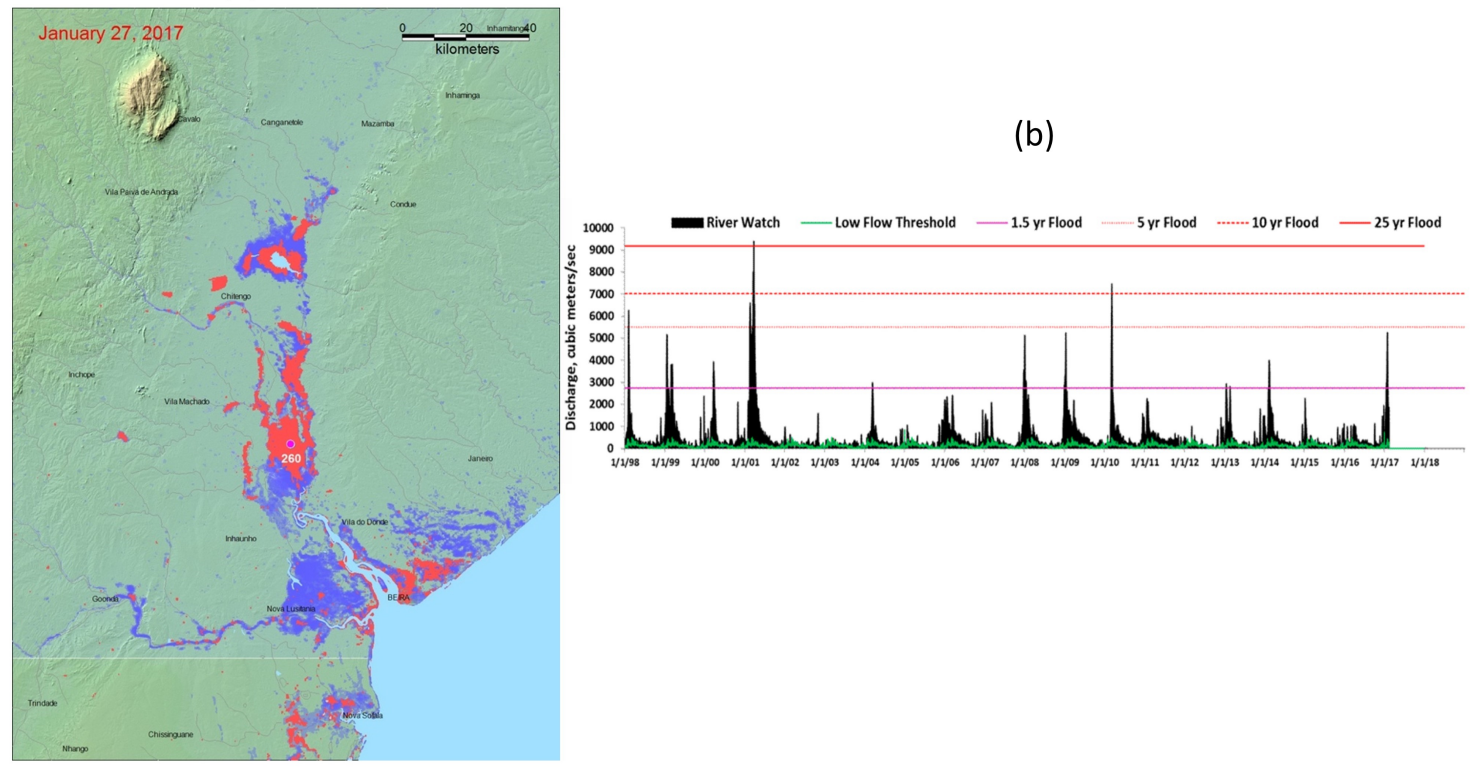

Figure 2. DFO's “River Watch" service. (a) Large scale flood mapping, Mozambique, from MODIS $250 \mathrm{~m}$ and Sentinels SAR $15 \mathrm{~m}$ data. Red areas are flooding end of January 2017, dark blue areas are previously mapped flooding since MODIS became operational in late 1999. Light blue is permanent water mapped in the NASA SWBD (SRTM mission-derived surface water, winter 2000). (b) DFO's River Watch processor provided these results in near real time at Satellite Gauging Site 260 (purple dot in center of map); see latest flood peak of January 2017 in this microwave radiometry-derived discharge time series, 1998-present). Flood reached close to but did not exceed the 5-year recurrence interval threshold, and so was classified as "moderate" flooding.

NASA's near real-time (NRT) flood mapping (http: / / oas.gsfc.nasa.gov / floodmap) is similar to the DFO, and since 2012 feeds its automated product to the DFO. The LANCE (https: / / earthdata. nasa.gov/about/science-system-description/eosdis-components/lance) processing system at NASA GSFC (Goddard Space Flight Center) provides such products typically within a few hours of satellite overpass. Flooded area is detected using a ratio of MODIS bands in the visible and near infrared at $250 \mathrm{~m}$ spatial resolution. The impact of clouds is minimized by compositing images typically over two or more days. Flooding is classified as anomaly to a reference water layer denoting "normal" water extent.

\subsection{The Global Flood Detection System}

The Global Disaster Alert and Coordination System (GDACS) hosts the Global Flood Detection System (GFDS, http:/ / www.gdacs.org/flooddetection) that monitors floods worldwide using NRT passive microwave remote sensing from the Advanced Microwave Scanning Radiometer-Earth Observing System (AMSR-E), a product that is used by the DFO to determine satellite-based discharge (see DFO's "River Watch" product). Changes in surface water over a large area $(10 \times 10 \mathrm{~km}) \mathrm{can}$ be observed as it affects the emitted microwave signal. This allows the system to flag the area as flooded when surface water significantly increases [24]. Time series are calculated in more than 10,000 monitoring areas, along with flood maps and animations.

\subsection{The Global Flood Monitoring System}

Real-time quasi-global hydrological calculations at 0.125 degree for river networks and $1 \mathrm{~km}$ resolution for floodplain inundation simulations are performed with the University of Maryland's Global Flood Monitoring System (UMD's GFMS [25], http://flood.umd.edu). The GFMS is 
a NASA-funded experimental system that originally used real-time TRMM Multi-satellite Precipitation Analysis (TMPA) data and now the iMERG (Integrated Multi-satellitE Retrievals for GPM) product from the Global Precipitation Measurement (GPM) mission (Figure 3). This system also issues flood forecasts with 4 to 5-day lead time, based on NWP precipitation, and mapping of inundation at a 3-h time step.

Although at a relatively low resolution, the timely delivery of system outputs and its lead-time prediction capability make it very attractive to flood relief services and flood disaster response organizations worldwide, such as the UN WFP.

The extent of a flood as estimated by GFMS during large events is regularly validated against satellite flood maps from the DFO and other data, such as gauges in some locations. Although a high level of accuracy is not always achievable and varies by location, the system typically reproduces the general extent and identifies which rivers are affected. Over certain types of complex terrain, satellite estimation of precipitation can be highly inaccurate, and ground information for the model, including topography, is also limited in accuracy. In regions where geospatial data and services for event observation are abundant and other local datasets and monitoring stations provide high accuracy information (e.g., the U.S., Canada, Europe, Australia, etc.), GFMS may add value by forecasting situational awareness over large scales. However, in areas and countries without extensive weather and monitoring networks on the ground, the satellite-view of floods, as delivered by GFMS and the $\mathrm{DFO}$, is often the only source of actionable information.

(a)

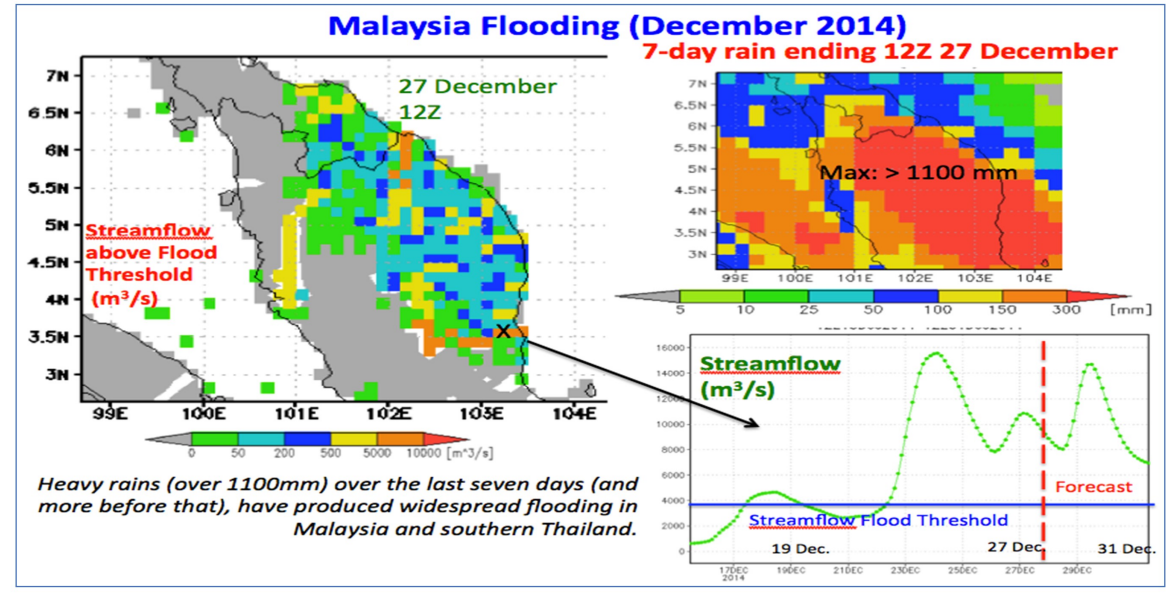

(b)

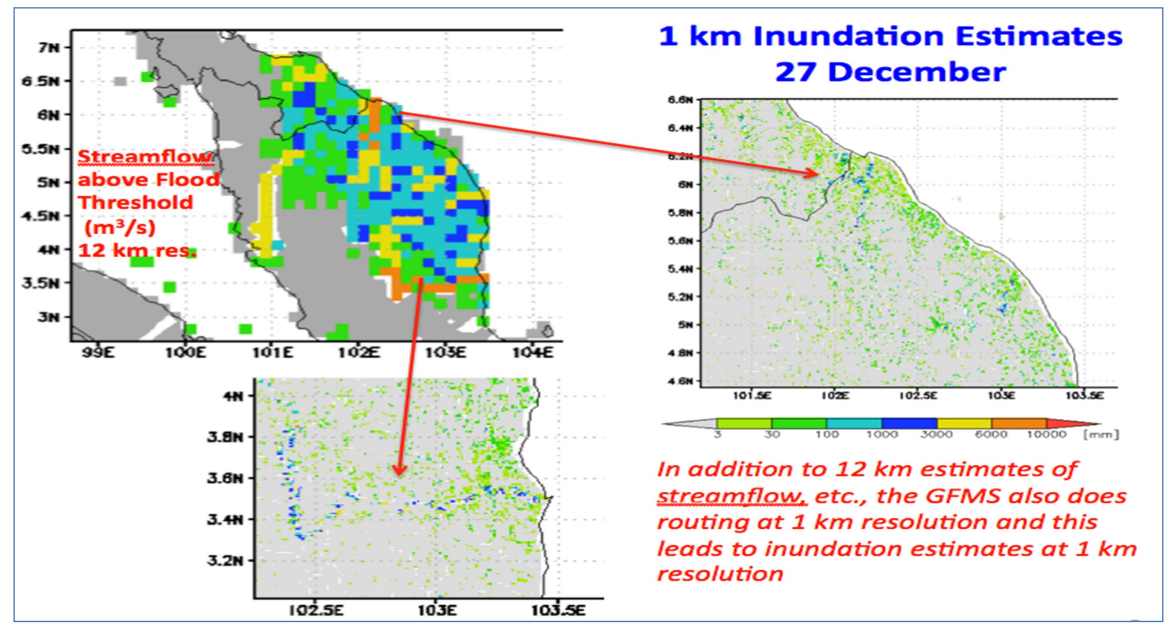

Figure 3. The Global Flood Monitoring System. (a) Malaysia flooding in December 2014. (b) $1 \mathrm{~km}$ inundation estimates over affected areas in Malaysia. 


\subsection{Other Rapid Mapping Systems}

\subsubsection{Automated SAR Flood Mapping with ESA's G-POD}

ESA hosts a SAR-based mapping tool on their Grid-Processing on Demand (G-POD) system (http://gpod.eo.esa.int), which is currently operated as a free registration-based service. Once in operation, any registered user can query the ESA SAR database for a flood image and retrieve an automatically generated flood map (Figure 4). The mapping algorithm calibrates a statistical distribution of "open water" backscatter values of SAR images of floods. Then, a radiometric thresholding provides the seed region for a region growing process. Change detection is included as an additional step which minimizes over-detection of flooded area [26]. Using two case studies, evaluation showed that the performance matches that of optimized manual approaches. Their automated flood mapping algorithm works on different SAR image modes and resolutions.

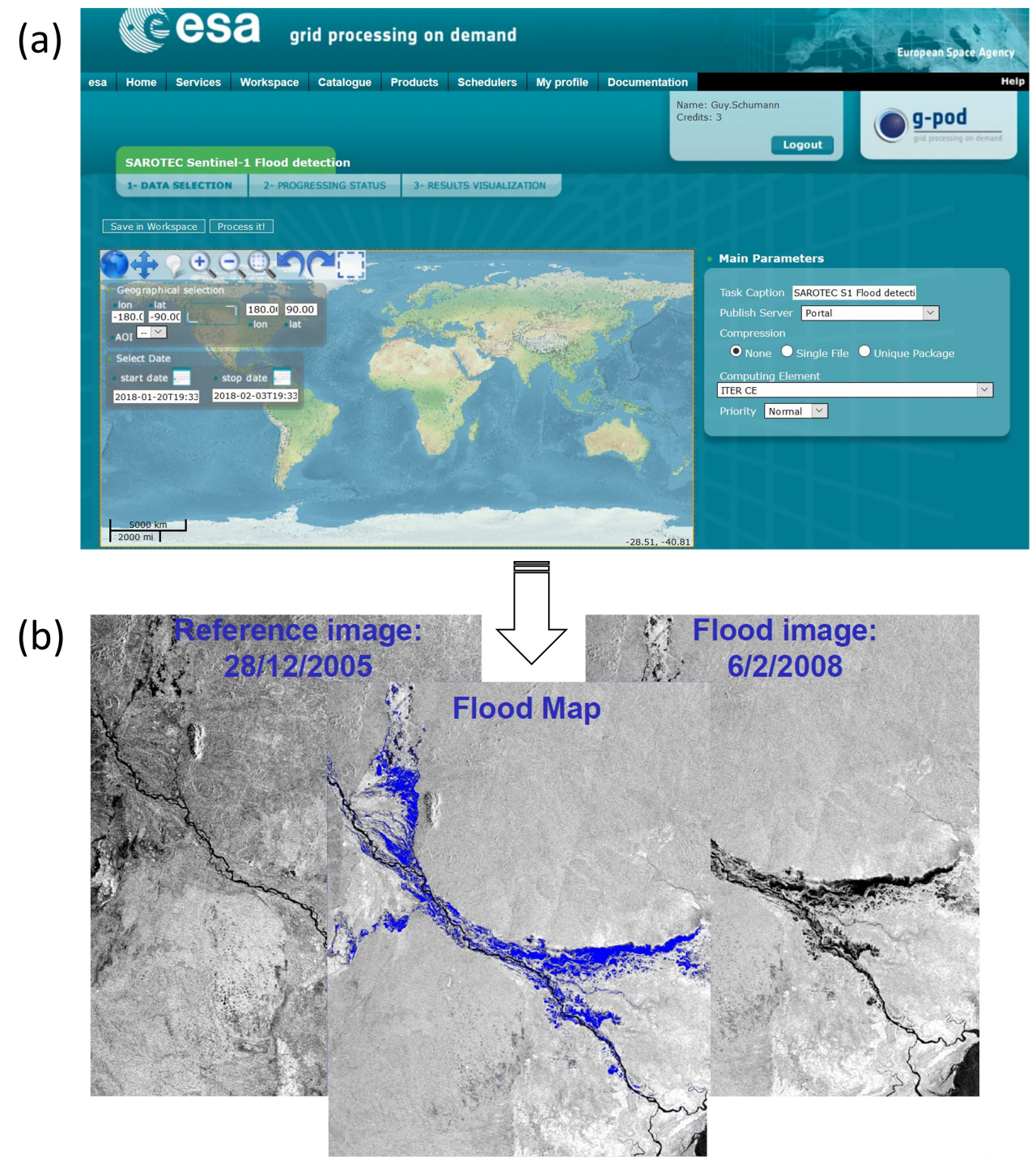

Figure 4. ESA's SAROTEC Flood Detection tool. (a) Online user interface of the ESA G-POD system (for registered users). (b) Flood map of the February 2008 flood event on the Zambezi River in Mozambique, generated with the automated processing chain (image in (b) after [27]). 


\subsubsection{DLR's ZKI}

The German Aerospace Centre's Crisis Information Centre (DLR's ZKI) monitors flood disasters by tasking its TerraSAR-X satellite and, as part of the International Charter, has access to other tasked satellites that may provide relevant crisis data. In addition, the data archive is searched for matching pre-disaster satellite scenes. According to DLR, during the first six hours after the activation of ZKI, reference maps based on archive satellite data providing a first overview of the affected area can be made available to relief organizations. Newly acquired post-disaster satellite data is used to assess and monitor the ongoing crisis situation, i.e., delineate the affected areas and estimate the damages caused by the disaster (see Martinis et al. [28] for more detail on the methodological approach).

\subsubsection{NASA JPL's ARIA}

The ARIA Center (https://aria.jpl.nasa.gov), a joint venture co-sponsored by the California Institute of Technology (Caltech) and by the NASA Jet Propulsion Laboratory (JPL), provides an infrastructure to generate imaging products primarily from COSMO-SkyMed and ALOS PALSAR 2 in near real-time that can improve situational awareness for disaster response. The ARIA Center also plans to provide automated imaging and analysis capabilities necessary to keep up with the imminent increase in raw data from geodetic imaging missions planned for launch by NASA, as well as international space agencies. Analyses of these data sets during floods are currently handcrafted following each event and so may need a more timely, automated production for an operational response assistance during natural disasters.

\subsubsection{Rapid Flood Mapping from NOAA's VIIRS Sensor}

The Visible Infrared Imaging Radiometer Suite (VIIRS) instrument is one of the five major EO instruments onboard NOAA's Suomi-NPP and JPSS satellites, essentially a continuation of NOAA's AVHRR legacy sensors. With a very large swath width of $3060 \mathrm{~km}$, it provides full daily coverage of the Earth both during the day and at night.

Using VIIRS and the coastal flooding caused by Hurricane Sandy as a test case, Li et al. [29] present an approach to estimate the extent of large-scale floods in an operational setting (Figure 5). The approach estimates the water fraction from VIIRS 375-m imager data by applying a mixed-pixel linear decomposition and a dynamic nearest neighbor search method. By using the reflectance characteristics of the VIIRS visible, near-infrared and shortwave infrared channels, the method dynamically searches the nearby land and water end-members. As an optional post-processing step, based on simple physical characterization of water spreading, the low-resolution flood map from VIIRS can be downscaled to a higher spatial resolution using a digital elevation model; in their case, the output was downscaled to a $30 \mathrm{~m}$ pixel spacing.

More recently, the same algorithm is also applied to images from GOES-R/ABI (Geostationary Operational Environmental Satellite-R/Advanced Baseline Imager). GOES-R/ABI scans the Earth surface of CONUS every five minutes with a resolution of $0.5-2 \mathrm{~km}$, which can provide many more opportunities for cloud-free acquisitions during a flood event. Merging flood maps from both the GOES-R/ABI and VIIRS in near real-time can add substantial value to the final map product being delivered to the flood response community. The delivery system currently in place is the Unidata AWIPS (https://www.unidata.ucar.edu/software/awips2), which is a meteorological display and analysis package originally developed by the National Weather Service and Raytheon to support non-operational use in research and education by UCAR member institutions. 


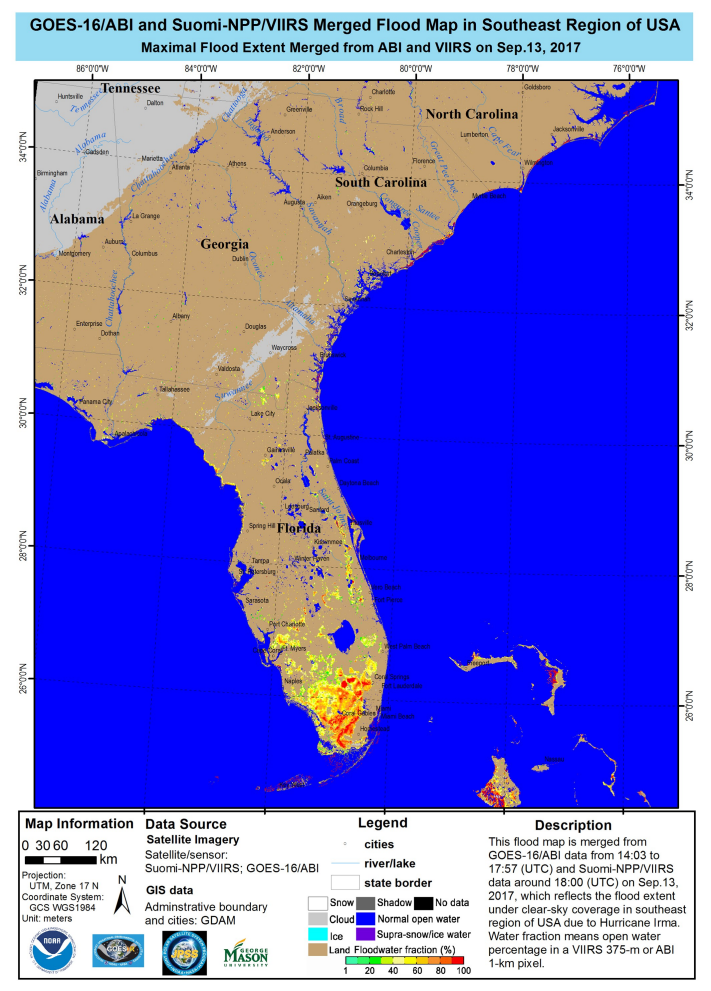

Figure 5. Merged flood map from Suomi-NPP/VIIRS data and GOES-16/ABI data on 13 September 2017, which reflects the flood extent under clear-sky coverage in the Caribbean islands due to Hurricane Irma. Water fraction means open water percentage in a VIIRS $357 \mathrm{~m}$ or ABI $1 \mathrm{~km}$ pixel.

\subsection{Other International Initiatives}

\subsubsection{The International Charter}

The International Charter (https:/ / www.disasterscharter.org) provides a unified system of space data acquisition and delivery to those affected by disasters. Space agency members commit resources to support the provisions of the Charter which can be activated by pre-defined authorized users. Due to its ongoing success over the last decades, the Charter is now widening access to satellite imagery for disaster response to any national disaster management authority without the need for membership (https:/ / disasterscharter.org/documents/10180/187832/CHARTER_UA_ENG.pdf).

\subsubsection{The EC Copernicus Programme}

Europe, at the European Commission (EC) level, has developed a satellite- and model forecast-aided disaster response capability. The EC Copernicus programme, previously known as the GMES (Global Monitoring for Environment and Security) service, is establishing a European capacity for Earth Observation. Its Emergency Management Service (EMS, http:/ / emergency.copernicus.eu) is providing several operational services during disasters, including flood mapping from satellite images, in particular SAR, acquired for instance during activation of the International Charter. Most recently, For disasters in the United States, Copernicus EMS was activated during the devastating Louisiana summer 2016 floods and for the Hurricane Matthew flood disaster in October of 2016 as well as during the devastating 2017 hurricane season (including Harvey and Maria).

\subsubsection{The Global Flood Partnership}

Under the leadership of the Joint Research Centre (JRC) and with the close collaboration of the Dartmouth Flood Observatory, key personnel from the international scientific community with 
a common interest in global flood forecasting and monitoring systems form the Global Flood Working Group (GFWG). To strengthen the partnership in strategic areas and increase efficiency, the GFWG proposed the Global Flood Partnership (GFP, https:/ / gfp.jrc.ec.europa.eu) whose overall objective is the development of flood observational and modeling infrastructure, leveraging on existing initiatives for better predicting and managing flood disaster impacts and flood risk globally. The Partnership, part of the Group on Earth Observations (GEO), aims to achieve this by bringing together the scientific community, service providers, national flood and emergency management authorities, humanitarian organizations and donors to provide operational, globally-applicable flood forecasting and monitoring tools and services, complementing national capabilities.

The substantial efforts already put in by the GFP to meet humanitarian needs during significant events through the group's mailing list. Here, special emphasis should be given to both the collaborative effort exhibited by GFP members and efforts to help user groups become better educated on available products. This has been reported in detail and assessed using recent event examples in a recent paper by Alfieri et al. [20].

\subsubsection{The CEOS Flood Pilot}

The working group on disasters of the Committee on Earth Observation Satellites (CEOS), part of GEO, aims to deliver satellite data seamlessly to end-users during natural disasters. The working group's Flood Pilot (http:/ / ceos.org/ourwork/workinggroups/disasters/floods) has been leveraging and coordinating several ongoing projects, particularly in three regions (the Caribbean, southern Africa and Southeast Asia). One of the pilot's main objectives has been to create a Global Flood Dashboard to serve as a "one-stop shop" for information from several existing systems (mostly from ALOS PALSAR 2, COSMO-SkyMed, RADARSAT-2) for monitoring and predicting floods in real-time, as also argued by Schumann and Domeneghetti [3] in an Invited Commentary on the proliferation of satellite data. In general, pilot regions have been encouraged to develop a basic capacity to access data and include them in their decision-making process. However, without continued support, the flood pilot of CEOS is unlikely to continue much beyond 2017 and will probably be discontinued.

\section{Matching Capabilities and Needs}

The systems and initiatives highlighted in the previous sections are showcasing notable progress in a time where the need and desire for geospatial datasets to inform decision-making processes during disasters are clearly increasing. However, in recent years, response coordination between EO product developers and decision-makers during flood disasters has only slowly, albeit steadily, improved.

This said, recent response coordination efforts have helped get value-added products into the right hands and also shorten the latency between data acquisition and product delivery considerably. This, in turn, has ensured more efficient and more effective field operations and a higher degree of interoperability, which is ever more important in an era of geospatial data proliferation [3]. A "new community of practice" has resulted from those coordinated efforts, which, of course, require resources, both in time and money, and can be extremely challenging, particularly in the event of simultaneous disasters or large successive events that have manifested themselves several times in the last decade, particularly for floods.

From an end-user perspective, Table 3 lists major challenges and needs, and proposes appropriate actions. The table is a comprehensive summary of a round-table discussion at a NASA-funded workshop on flood response in June 2016 that brought together end-users, decision-makers, scientists and product developers to discuss and formalize a coordinated domestic and global response to flood disasters [30]. 
Table 3. Common and overlapping challenges or needs identified as well as the associated action that has been defined during the 2016 Flood Response Workshop [30].

\begin{tabular}{|c|c|c|}
\hline Challenge/Need & Action & Comment \\
\hline Integrating optical \& SAR (plus imagery from other agencies) & \multirow{3}{*}{$\begin{array}{l}\text { Extend SAR capabilities \& integrate with optical and } \\
\text { models \& improve image processing algorithms } \\
\text { (improve on each capability). Use assimilation } \\
\text { techniques to optimize data-model integration }\end{array}$} & This should be a priority action \\
\hline $\begin{array}{l}\text { Resolve various flood detection/processing issues } \\
\text { (cloud cover, flooded vegetation, "normal water" layer) }\end{array}$ & & $\begin{array}{l}\text { Can be implemented under research grants and be reported in scientific } \\
\text { journals as well }\end{array}$ \\
\hline $\begin{array}{l}\text { Better flood model input/forcing data } \\
\text { (+ reservoirs, dams \& defences) }\end{array}$ & & $\begin{array}{l}\text { This is of high importance but may require efforts over a longer period } \\
\text { and additional data }\end{array}$ \\
\hline Routine validation of EO products \& services & \multirow[b]{2}{*}{ Routine validation \& fast computation/turnaround } & \multirow[b]{2}{*}{$\begin{array}{l}\text { These are two items that should be regarded as top priority and can be } \\
\text { resolved easily with some coordinated efforts }\end{array}$} \\
\hline $\begin{array}{l}\text { Identify "top" EO products through vetting and through better } \\
\text { understanding of specific end-user needs as well as historical } \\
\text { analysis of past major events }\end{array}$ & & \\
\hline Solve restrictive data licensing & \multirow[b]{2}{*}{ Free licensing/availability } & \multirow[b]{2}{*}{$\begin{array}{l}\text { Licensing is a top priority but may take time and } \mathrm{HQ} \text {-level coordinated } \\
\text { efforts from multiple agencies and other organizations }\end{array}$} \\
\hline $\begin{array}{l}\text { Data \& products under Creative Commons licensing } \\
\text { (open-access) }\end{array}$ & & \\
\hline Improve product training \& feedback mechanisms & \multirow{3}{*}{$\begin{array}{l}\text { Link up services and end-users } \\
\text { (direct involvement \& feedback) }\end{array}$} & \multirow{3}{*}{$\begin{array}{l}\text { These action items are ongoing through various activities and programs } \\
\text { such as SERVIR, CEOS, ARSET, DEVELOP etc. but need a more } \\
\text { coordinated effort, probably with guidance from NASA HQ }\end{array}$} \\
\hline Connect to private sector capabilities & & \\
\hline Identify point of contacts (PoC) to act ahead of disaster & & \\
\hline Product standardization & \multirow[b]{3}{*}{ Create one-stop-shop } & $\begin{array}{l}\text { This is a crucial element and is easy enough to implement through } \\
\text { inclusion in project deliverables for instance }\end{array}$ \\
\hline Improve product \& service turnaround & & \multirow{2}{*}{$\begin{array}{l}\text { Creating a one-stop-shop is a top priority but needs much coordinated } \\
\text { effort and continuous management of such a site is crucial. It is } \\
\text { recommended to build upon an existing platform, such as the Dartmouth } \\
\text { Flood Observatory (during high impact events, the DFO already pulls and } \\
\text { displays data from various sources) }\end{array}$} \\
\hline $\begin{array}{l}\text { Single map display using separate layers from different products } \\
\text { (SAR, optical, models, socio-economic data) }\end{array}$ & & \\
\hline
\end{tabular}


The following three subsections illustrate the main challenges typically encountered during disasters. It is obvious that without a clear reality check, it is difficult to manage expectations, which is needed to match capabilities and needs.

\subsection{Daily Status Updates}

It is very common that decision-makers require at least daily status updates on affected regions and at spatial resolutions detailed enough to assess local infrastructure assets at risk. However, nontrivial issues, such as inadequate satellite revisit times, adverse weather conditions (e.g., cloud cover, fog, or heavy precipitation) and densely vegetated and built-up areas, are typically hindering scientists and product developers to meet end-user expectations.

The above clearly illustrates a situation where it is crucial to manage expectations adequately by matching scientific and technical capabilities with end-user needs and expectations.

\subsection{High-Resolution Maps at Any Time}

Furthermore, there is a clear need for more high-resolution open-access satellite imagery during flood relief operations. River reaches tend to be monitored and studied at much smaller scale than that typically acquired with wide-swath EO imagery, and therefore monitoring those reaches for situational awareness does actually require much higher spatial resolutions. Very high-resolution images $(<5 \mathrm{~m})$ also become a prerequisite when monitoring and modeling urban areas where most assets at risk of flooding are located and where city-block scale often dictates the ability to model or monitor flood inundation patterns accurately [31]. Here, airborne repeat overpasses are commonly the preferred choice, or indeed drones, but from space, constellations of multiple fine resolution SAR systems may present a possible solution or even alternative. COSMO-SkyMed for instance can get a $3 \mathrm{~m}$ image sequence with a time from request to acquisition of the first image of 26-50 h, then subsequent images at 12-h intervals.

At present, however, the constellation capability of COSMO-SkyMed is not actually readily and freely available to the flood mapping community during disasters since the Italian Space Agency (ASI) is currently not a member of the International Charter (https:/ / disasterscharter.org/en/web/guest/ charter-members). This said, high-resolution acquisitions from individual satellites (e.g., TerraSAR-X, RADARSAT-2) or from the available constellations of commercial companies (such as Planet or DigitalGlobe) or of ESA's Sentinel-1A and B under the Charter, Copernicus or indeed within an operational system such as ESA's G-POD FAIRE (Grid-Processing On Demand Fast Access to Imagery for Rapid mapping Exploitation, http:/ / gpod.eo.esa.int) or the DFO, actionable flood maps can be made available to the users several hours after acquisition. This form of rapid delivery of fine resolution, actionable information is now technically feasible and might be a common form of dissemination in the near future.

As argued by Schumann et al. [32], although systematic, high-resolution, and lower resolution but wide-area observations are now all possible during flood disaster, the full potential of EO data can only be unlocked when combining all available data in an intelligent way. This major challenge is still clearly posed during every large flood disaster.

\subsection{The Maze of Geospatial Information}

With all this wealth of EO products and services produced and disseminated, there is however a noticeable under-utilization of this information. Most of the reasons for this situation relate to the relative novelty of these types of data. There is generally very limited time and personnel available during an emergency situation to understand, process and handle new types of geospatial datasets. Also, limited near-real time data accessibility, bandwidth and sharing capacity make product and data distribution cumbersome. Further, oftentimes, incompatibility between user platforms and geospatial data formats hinder more widespread use of new EO products and services; or, data availability may be simply unknown and data latency may be inadequate. Many of the service interfaces are not 
intuitive and user-friendly (often require certain skill sets) and requirements to run specific queries for complex datasets from multiple platforms can be quite confusing and time consuming for layperson end-users such as emergency responders, especially during disaster response. However, the largest gap that needs to be bridged is the limited understanding by scientists and engineers about end-user product and timing needs, which is also discussed by Hossain et al. [33] as a widespread concern in the applied Earth sciences arena.

While all these challenges represent a clear limitation in fulfilling the needs of the decision-maker, they create an opportunity for innovation to develop products that deliver better actionable information, as illustrated in Table 4.

Table 4. Product attributes that are important to users.

\begin{tabular}{|c|c|}
\hline \multicolumn{2}{|r|}{ User Needs } \\
\hline Reliability & $\begin{array}{l}\text { Will this product be available at any time? Frequent outages } \\
\text { discourage the user and cause them to go to a different product }\end{array}$ \\
\hline Accessibility & $\begin{array}{l}\text { In case of issues with access to data, is there any point of contact to } \\
\text { assist with questions, especially during large scale emergencies? }\end{array}$ \\
\hline Authoritative & $\begin{array}{l}\text { Given the myriad of data streams and services, is there a consensus } \\
\text { among the flood expert community that the specific imagery, data } \\
\text { and/or analysis being delivered for a particular event is the best } \\
\text { possible option in terms of timeliness, accuracy and resolution? What } \\
\text { is the coordination mechanism and is the activation/action process } \\
\text { clear to the end-user community? }\end{array}$ \\
\hline Sustainability & $\begin{array}{l}\text { Is the product or service sustainable throughout the emergency cycle } \\
\text { from preparedness and mitigation through to the recovery period? } \\
\text { Some services deliver a few post-event products only during major or } \\
\text { selected emergencies }\end{array}$ \\
\hline Ground-truthing & $\begin{array}{l}\text { Are after-event reports from the affected area available which can } \\
\text { attest to or refute the usefulness of the provided EO imagery, data and } \\
\text { analysis on the outcome of the crisis, specifically on the lives and } \\
\text { livelihoods of the affected populations? This information is invaluable } \\
\text { in order to correct or finetune the process for future events. Were any } \\
\text { local flood experts consulted before or during the event? }\end{array}$ \\
\hline $\begin{array}{l}\text { Accuracy/Clear Description } \\
\text { of Biases \& Uncertainties }\end{array}$ & $\begin{array}{l}\text { Every product has strengths and weaknesses as well as associated } \\
\text { uncertainties. It is most important to share weaknesses } \\
\text { and uncertainties, so users can adjust for biases, and use the product } \\
\text { more confidently. Otherwise errors may seem random which discourage } \\
\text { user from using the product for future events }\end{array}$ \\
\hline $\begin{array}{l}\text { Ideas on How to } \\
\text { Apply Product }\end{array}$ & $\begin{array}{l}\text { Help users brainstorm and demonstrate how data could be applied for } \\
\text { different scenarios. For instance, identifying flooded roads/bridges } \\
\text { and alternative humanitarian corridors during a response, identifying } \\
\text { suitable sites for helicopter landings, temporary shelters, } \\
\text { warehousing, response hubs or delineating evacuation zones, } \\
\text { estimating affected populations, etc. Do you have any examples from } \\
\text { other users or recent flood emergencies? Users may not always know } \\
\text { all possible applications or what could be available }\end{array}$ \\
\hline Appropriate Format & $\begin{array}{l}\text { At least some users have low bandwidth, especially during } \\
\text { emergencies. Is data access clear and easy? Is the data GIS and map } \\
\text { friendly? Can the provided analysis or imagery be easily inserted into } \\
\text { a report during emergency? }\end{array}$ \\
\hline
\end{tabular}

\section{Prospective Actions}

To address the many challenges that exist in making EO data more readily usable and actionable in assisting flood disaster preparedness and response, the scientific community should seek closer 
collaboration with end-users [33]. This advocacy was also an open discussion at the 2017 annual meeting of the Global Flood Partnership. Table 5 outlines the benefits and requirements of an effective partnership between product users and developers in the context of flood disaster response activities. What becomes very apparent is that, yet again, expectations on both sides should be matched and that there is a need for more open communication between the different actors involved on both sides.

Table 5. Benefits and actions to ensure effective partnerships between product users and developers.

\begin{tabular}{lll}
\hline Effective Partnerships & Benefit & Action \\
\hline $\begin{array}{l}\text { Include User in Evaluation } \\
\begin{array}{l}\text { Process-help users } \\
\text { drive innovation }\end{array}\end{array}$ & $\begin{array}{l}\text { User can provide critical feedback, } \\
\text { and sometimes find new errors. } \\
\text { Identify user misunderstanding } \\
\text { of product }\end{array}$ & $\begin{array}{l}\text { Evaluate product based on specific } \\
\text { user needs/scientist needs. Survey } \\
\text { forms often too vague to evaluate } \\
\text { source of problems or identify } \\
\text { user misunderstandings }\end{array}$ \\
\hline \multirow{2}{*}{$\begin{array}{l}\text { Reliable communication means } \\
\text { problems addressed right away } \\
\text { before next event. Communication } \\
\text { becomes easier and shorter awhile } \\
\text { after partnership established. }\end{array}$} & $\begin{array}{l}\text { Informal emails; test cases ahead } \\
\text { or during event to maximize user } \\
\text { understanding and application } \\
\text { of product }\end{array}$ \\
\hline Determine Customer Needs & $\begin{array}{l}\text { Clear understanding of where new } \\
\text { developments may be needed, and } \\
\text { new ideas for innovation }\end{array}$ & $\begin{array}{l}\text { When beginning a new } \\
\text { partnership, discuss user concerns, } \\
\text { responsibilities and goals. } \\
\text { Continue to re-evaluate yearly }\end{array}$ \\
\hline
\end{tabular}

Schumann and Domeneghetti [3] argued that a step in the right direction would be to build a "one-stop-shop" (i.e., data portal) dedicated to the remote sensing of floods. The idea of a data clearinghouse or one-stop-shop is not new (see, for example, the USGS Hazards Data Distribution System (HDDS) and related services, all under the USGS emergency operations portal, https:/ / hdds.usgs.gov) and is also a top priority action item that came out of the NASA Flood Response Workshop mentioned earlier [30]. This platform could collect EO imagery and products and synthesize knowledge as well as data from past events and experiences. Decision-makers need to be able to pull data and products from this portal at low bandwidth and latency, and request tailored information layers as needed for their operations. Other relevant information could be made available alongside remote sensing data of floods, such as output layers from models such as produced for instance by flood forecast or NRT event models. Those model computations can then be complemented and verified by social media streams and help pinpoint target regions for satellite image acquisition and delivery of flood products. Of course, this functionality requires the highest level of interoperability (Figure 6) between the different actors and systems of the flood response community since it all needs to integrate seamlessly with end-user operation systems and platforms and ideally also be accessible on any device. In this context, strengthening public-private partnerships would allow access to high-end capabilities and leveraging advanced data interoperability standards and service protocols developed by the geospatial industry sector. 


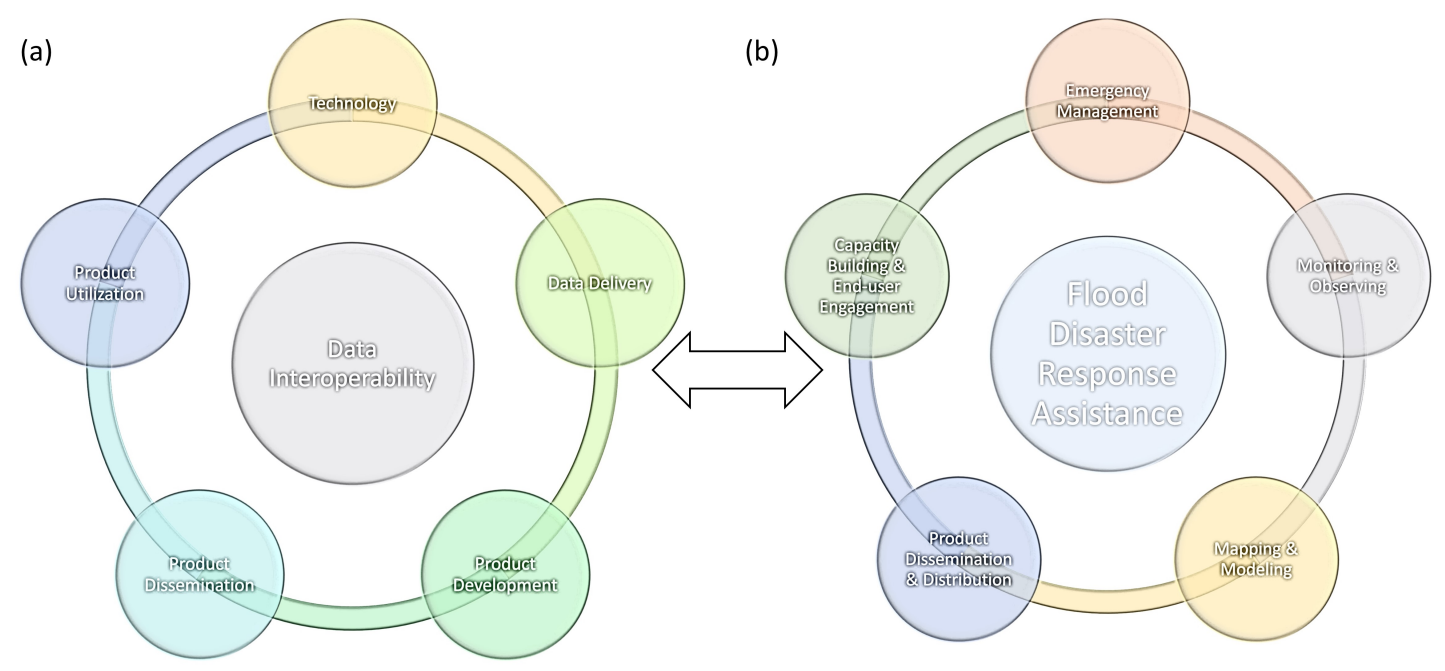

Figure 6. Graphical illustration of the importance of data and product interoperability showing (a) the different components that are typically needed to get seamlessly from a data acquisition technology to product utilization. Such an interoperability mechanism needs to be adopted by the many actors involved in flood disaster response shown in (b) (modified after [27,30]).

Table 6 provides a top-priority wish list of the community of practice in flood response, illustrated in Figure 6. Regardless of where this one-stop-shop resides and who manages it, it would not only organize and structure data availability better thereby clarifying existing confusion over data and products; it would also help meet expectations and add further value to the various EO products and services. At the same time, the end-user community should have the opportunity to provide feedback on data and products, which in turn should be used to improve the different types of information disseminated.

Table 6. Top priorities for the "Flood Response Community".

\begin{tabular}{|c|c|c|c|c|}
\hline Emergency Management & Monitoring \& Observing & Mapping \& Modeling & $\begin{array}{l}\text { Product Dissemination \& } \\
\text { Distribution }\end{array}$ & $\begin{array}{l}\text { Capacity Building \& } \\
\text { End-User Engagement }\end{array}$ \\
\hline $\begin{array}{l}\text { Push data and products out } \\
\text { in } 12 \text { - to } 24 \text {-h intervals, } \\
\text { within capabilities (ask for } \\
\text { assistance with resources as } \\
\text { needed and manage } \\
\text { expectations) }\end{array}$ & $\begin{array}{l}\text { One-stop-shop (should also } \\
\text { include future acquisitions), } \\
\text { where communities can } \\
\text { pull rather than push data } \\
\text { and products }\end{array}$ & $\begin{array}{l}\text { Automated polygon } \\
\text { (shapefile) generation of } \\
\text { flood disaster location to } \\
\text { target Earth observation } \\
\text { data acquisition and } \\
\text { products, especially at the } \\
\text { international level }\end{array}$ & $\begin{array}{l}\text { Single access point } \\
\text { (one-stop-shop) that allows } \\
\text { automated product } \\
\text { delivery system }\end{array}$ & $\begin{array}{l}\text { Build trust in the products } \\
\text { and report value to } \\
\text { community: One-stop-shop } \\
\text { needs to have products that } \\
\text { are tailored to user needs } \\
\text { and allow for feedback }\end{array}$ \\
\hline
\end{tabular}

\section{Conclusions}

Since the beginning of the twenty-first century, there has been a steady proliferation of satellite sensors apt to assist during disaster response and recovery operations. The ability to monitor floods with sensors onboard satellites is well known and in recent years, progress in applied research has led to a significant increase in maturity of EO-based products and services to assist flood disaster response at the global level.

This article critically assessed the utility of remote sensing from satellites to map and monitor floods with the aim to assist disaster response activities. Proliferation of EO data over recent years has caused a shift from a data-poor to a data-rich environment [11]. Consequently, innovative methods and products from these data have been developed, which led not only to better understanding of flood processes at various spatial and temporal scales but also to global initiatives and applications that utilize and promote remote sensing for improved decision-making activities, particularly in developing nations and during emergencies. 
Although the value that remote sensing can offer to flood disaster response activities is growing rapidly, many challenges still lie ahead. Ensuring sustainable and interoperable use as well as optimized distribution of remote sensing products and services through consistent and organized coordination mechanisms need to be the top priorities. Another clear need is end-user driven validation and feedback in order to eventually make satellite-based products and services more credible to the decision-maker. At the same time, it is paramount to manage expectations and, if satellite-based applications are to achieve the required readiness level for decision-making, scientists and engineers need to be honest and clear about what exactly science and technology can offer and what the capabilities of the many products and services being offered mean to end-users.

Author Contributions: All authors contributed equally to the assessment and the writing of this paper.

Funding: This paper was supported through funding from the National Aeronautics and Space Administration (Grant Numbers: NNX16AH57G, NNX17CG65P and 80NSSC18C0121).

Acknowledgments: G.J-P. Schumann's time and effort on this paper were supported by grants from the National Aeronautics and Space Administration (Grant Numbers: NNX16AH57G, NNX17CG65P and 80NSSC18C0121).

Conflicts of Interest: The authors declare no conflict of interest. The founding sponsors had no role in the design of the study; in the collection, analyses, or interpretation of data; in the writing of the manuscript, and in the decision to publish the results.

\section{Abbreviations}

The following abbreviations are used in this manuscript and not defined upfront:

$\begin{array}{ll}\text { ARIA } & \text { Advanced Rapid Imaging and Analysis } \\ \text { ASI } & \text { Italian Space Agency } \\ \text { AWIPS } & \text { Advanced Weather Interactive Processing System } \\ \text { CEOS } & \text { Committee on Earth Observation Satellites } \\ \text { DFO } & \text { Dartmouth Flood Observatory } \\ \text { DLR } & \text { German Aerospace Center (Deutsches Zentrum für Luft- und Raumfahrt) } \\ \text { EO-1 } & \text { Earth Observing-1 (satellite mission) } \\ \text { ESA } & \text { European Space Agency } \\ \text { GOES-R/ABI } & \text { Geostationary Operational Environmental Satellite-R/Advanced Baseline Imager } \\ \text { GSFC } & \text { Goddard Space Flight Center } \\ \text { IMERG } & \text { Integrated Multi-satellitE Retrievals for GPM } \\ \text { JPL } & \text { Jet Propulsion Laboratory } \\ \text { LIST } & \text { Luxembourg Institute of Science and Technology } \\ \text { MODIS } & \text { Moderate Resolution Imaging Spectroradiometer } \\ \text { NASA } & \text { National Aeronautics and Space Administration } \\ \text { UCAR } & \text { University Corporation for Atmospheric Research } \\ \text { UMD } & \text { University of Maryland } \\ \text { ZKI } & \text { Center for Satellite Based Crisis Information }\end{array}$

\section{References}

1. Deutsch, M.; Ruggles, F. Optical data processing and projected applications of the ERTS-1 imagery covering the 1973 Mississippi River valley floods. JAWRA J. Am. Water Resour. Assoc. 1974, 10, 1023-1039. [CrossRef]

2. Robinove, C.J. Interpretation of a Landsat image of an unusual flood phenomenon in Australia. Remote Sens. Environ. 1978, 7, 219-225. [CrossRef]

3. Schumann, G.J.P.; Domeneghetti, A. Exploiting the proliferation of current and future satellite observations of rivers. Hydrol. Process. 2016, 30, 2891-2896. [CrossRef]

4. Schumann, G.J.P.; Moller, D.K. Microwave remote sensing of flood inundation. Phys. Chem. Earth Parts A/B/C 2015, 83-84, 84-95. [CrossRef]

5. Bates, P.D.; Horritt, M.S.; Smith, C.N.; Mason, D.C. Integrating remote sensing observations of flood hydrology and hydraulic modelling. Hydrol. Process. 1997, 11, 1777-1795. [CrossRef] 
6. Aronica, G.; Bates, P.D.; Horritt, M.S. Assessing the uncertainty in distributed model predictions using observed binary pattern information within GLUE. Hydrol. Process. 2002, 16, 2001-2016. [CrossRef]

7. Horritt, M.S.; Bates, P.D. Evaluation of 1D and 2D numerical models for predicting river flood inundation. J. Hydrol. 2002, 268, 87-99. [CrossRef]

8. Bates, P.D.; Horritt, M.S.; Aronica, G.; Beven, K. Bayesian updating of flood inundation likelihoods conditioned on flood extent data. Hydrol. Process. 2004, 18, 3347-3370. [CrossRef]

9. Schumann, G.J.P.; Bates, P.D.; Horritt, M.S.; Matgen, P.; Pappenberger, F. Progress in integration of remote sensing derived flood extent and stage data and hydraulic models. Rev. Geophys. 2009, 47. [CrossRef]

10. Di Baldassarre, G.; Schumann, G.; Bates, P.D. A technique for the calibration of hydraulic models using uncertain satellite observations of flood extent. J. Hydrol. 2009, 367, 276-282. [CrossRef]

11. Bates, P.D. Invited Commentary: Integrating remote sensing data with flood inundation models: How far have we got? Hydrol. Process. 2012, 26, 2515-2521. [CrossRef]

12. Hostache, R.; Lai, X.; Monnier, J.; Puech, C. Assimilation of spatially distributed water levels into a shallow-water flood model. Part II: Use of a remote sensing image of Mosel River. J. Hydrol. 2010, 390, 257-268. [CrossRef]

13. Matgen, P.; Montanari, M.; Hostache, R.; Pfister, L.; Hoffmann, L.; Plaza, D.; Pauwels, V.R.N.; De Lannoy, G.J.M.; De Keyser, R.; Savenije, H.H.G. Towards the sequential assimilation of SAR-derived water stages into hydraulic models using the Particle Filter: proof of concept. Hydrol. Earth Syst. Sci. 2010, 14, 1773-1785. [CrossRef]

14. Garcia-Pintado, J.; Neal, J.C.; Mason, D.C.; Dance, S.L.; Bates, P.D. Scheduling satellite-based SAR acquisition for sequential assimilation of water level observations into flood modelling. J. Hydrol. 2013. [CrossRef]

15. Manavalan, R. SAR image analysis techniques for flood area mapping-Literature survey. Earth Sci. Inf. 2017, 10, 1-14. [CrossRef]

16. Dasgupta, A.; Grimaldi, S.; Ramsankaran, R.A.; Pauwels, V.R.; Walker, J.P.; Chini, M.; Hostache, R.; Matgen, P. Flood Mapping Using Synthetic Aperture Radar Sensors From Local to Global Scales. In Global Flood Hazard; American Geophysical Union (AGU): Washington, DC, USA, 2018; Chapter 4, pp. 55-77. Available online: https: / agupubs.onlinelibrary.wiley.com/doi/pdf/10.1002/9781119217886.ch4 (accessed on 24 July 2018).

17. Klemas, V. Remote Sensing of Floods and Flood-Prone Areas: An Overview. J. Coast. Res. 2015, 31, $1005-1013$. [CrossRef]

18. Fayne, J.; Bolten, J.; Lakshmi, V.; Ahamed, A. Optical and Physical Methods for Mapping Flooding with Satellite Imagery. In Remote Sensing of Hydrological Extremes; Lakshmi, V., Ed.; Springer International Publishing: Cham, Switzerland, 2017; pp. 83-103.

19. Ban, H.J.; Kwon, Y.J.; Shin, H.; Ryu, H.S.; Hong, S. Flood Monitoring Using Satellite-Based RGB Composite Imagery and Refractive Index Retrieval in Visible and Near-Infrared Bands. Remote Sens. 2017, 9, 313. [CrossRef]

20. Alfieri, L.; Cohen, S.; Galantowicz, J.; Schumann, G.J.P.; Trigg, M.A.; Zsoter, E.; Prudhomme, C.; Kruczkiewicz, A.; de Perez, E.C.; Flamig, Z.; et al. A global network for operational flood risk reduction. Environ. Sci. Policy 2018, 84, 149-158. [CrossRef]

21. Brakenridge, R.; Anderson, E. Modis-Based Flood Detection, Mapping and Measurement: The Potential for Operational Hydrological Applications. In NATO Science Series IV Earth and Environmental Sciences, Proceedings of the NATO Advanced Research Workshop on Transboundary Floods-Reducing Risks Through Flood Management, Baile Felix, Romania, 4-8 May 2005; Marsalek, J., Stancalie, G., Balint, G., Eds.; NATO: Brussels, Belgium, 2006; Volume 72, pp. 1-12.

22. Fekete, B.M.; Vörösmarty, C.J.; Grabs, W. High-resolution fields of global runoff combining observed river discharge and simulated water balances. Glob. Biogeochem. Cycles 2002, 16. [CrossRef]

23. Brakenridge, G.R.; Cohen, S.; Kettner, A.J.; De Groeve, T.; Nghiem, S.V.; Syvitski, J.P.M.; Fekete, B.M. Calibration of satellite measurements of river discharge using a global hydrology model. J. Hydrol. 2012, 475, 123-136. [CrossRef]

24. De Groeve, T. Flood monitoring and mapping using passive microwave remote. Geomat. Nat. Hazards Risk 2010, 1, 19-35. [CrossRef]

25. Wu, H.; Adler, R.F.; Hong, Y.; Tian, Y.; Policelli, F. Evaluation of global flood detection using satellite-based rainfall and a hydrologic model. J. Hydrometeorol. 2012, 13, 1268-1284. [CrossRef] 
26. Matgen, P.; Hostache, R.; Schumann, G.; Pfister, L.; Hoffmann, L.; Savenije, H. Towards an automated SAR-based flood monitoring system: Lessons learned from two case studies. Phys. Chem. Earth 2011, 36, 241-252. [CrossRef]

27. Schumann, G.J.P. Satellite Remote Sensing of Floods for Disaster Response Assistance. In Remote Sensing of Hydrometeorological Hazards; Petropoulos, G.P., Islam, T., Eds.; CRC Press: Boca Raton, FL, USA, 2018; pp. 317-336.

28. Martinis, S.; Kersten, J.; Twele, A. A fully automated TerraSAR-X based flood service. ISPRS J. Photogramm. Remote Sens. 2015, 104, 203-212. [CrossRef]

29. Li, S.; Sun, D.; Goldberg, M.D.; Sjoberg, B.; Santek, D.; Hoffman, J.P.; DeWeese, M.; Restrepo, P.; Lindsey, S.; Holloway, E. Automatic near real-time flood detection using Suomi-NPP/VIIRS data. Remote Sens. Environ. 2018, 204, 672-689. [CrossRef]

30. Schumann, G.J.P. Flood Response Using Earth Observation Data and Products. In Proceedings of the NASA Flood Response Workshop, Greenbelt, ML, USA, 14-16 June 2016.

31. Schumann, G.J.P.; Bates, P.D.; Baldassarre, G.D.; Mason, D.C. The Use of Radar Imagery in Riverine Flood Inundation Studies. In Fluvial Remote Sensing for Science and Msnagement; Carbonneau, P.E., Piégay, H., Eds.; Wiley-Blackwell: Chichester, UK, 2012; pp. 115-140.

32. Schumann, G.J.P.; Frye, S.; Wells, G.; Adler, R.; Brakenridge, R.; Bolten, J.; Murray, J.; Slayback, D.; Policelli, F.; Kirschbaum, D.; et al. Unlocking the full potential of Earth observation during the 2015 Texas flood disaster. Water Resour. Res. 2016, 52, 3288-3293. [CrossRef]

33. Hossain, F.; Serrat-Capdevila, A.; Granger, S.; Thomas, A.; Saah, D.; Ganz, D.; Mugo, R.; Murthy, M.; Ramos, V.H.; Anderson, E.; et al. A Global Capacity Building Vision for Societal Applications of Earth Observing Systems and Data: Key Questions and Recommendations. Bull. Am. Meteorol. Soc. 2016. [CrossRef]

(C) 2018 by the authors. Licensee MDPI, Basel, Switzerland. This article is an open access article distributed under the terms and conditions of the Creative Commons Attribution (CC BY) license (http:/ / creativecommons.org/licenses/by/4.0/). 